\title{
A Study of Precipitation Climatology and Its Variability over Europe Using an Advanced Regional Model (WRF)
}

\author{
Hari Prasad Dasari ${ }^{*}$, Venkata Srinivas Challa ${ }^{2}$ \\ ${ }^{1}$ Physical Sciences and Engineering Division, King Abdullah University of Science and Technology, Thuwal, \\ Saudi Arabia \\ ${ }^{2}$ Radiological Safety and Environment Group, Indira Gandhi Center for Atomic Research, Kalpakkam, India \\ Email: ${ }^{\text {hari.dasari@kaust.edu.sa }}$
}

Received 14 February 2015; accepted 3 March 2014; published 6 March 2015

Copyright (C) 2015 by authors and Scientific Research Publishing Inc.

This work is licensed under the Creative Commons Attribution International License (CC BY). http://creativecommons.org/licenses/by/4.0/

(c) (i) Open Access

\section{Abstract}

In recent years long-term precipitation trends on a regional scale have been given emphasis due to the impacts of global warming on regional hydrology. In this study, regional precipitation trends are simulated over the Europe continent for a 60-year period in 1950-2010 using an advanced regional model, WRF, to study extreme precipitation events over Europe. The model runs continuously for each year during the period at a horizontal resolution of $25 \mathrm{~km}$ with initial/ boundary conditions derived from the National Center for Environmental Prediction (NCEP) 2.5 degree reanalysis data sets. The E-OBS 0.25 degree rainfall observation analysis is used for model validation. Results indicate that the model could reproduce the spatial annual rainfall pattern over Europe with low amounts $(250-750 \mathrm{~mm})$ in Iberian Peninsula, moderate to large amounts $(750-1500 \mathrm{~mm})$ in central, eastern and northeastern parts of Europe and extremely heavy falls $(1500-2000 \mathrm{~mm})$ in hilly areas of Alps with a slight overestimation in Alps and underestimation in other parts of Europe. The regional model integrations showed increasing errors (mean absolute errors) and decreasing correlations with increasing time scale (daily to seasonal). Rainfall is simulated relatively better in Iberian Peninsula, northwest and central parts of Europe. A large spatial variability with the highest number of wet days over eastern, central Europe and Alps ( 200 days/year) and less number of wet days over Iberian Peninsula ( $\leq 150$ days/year) is also found in agreement with observations. The model could simulate the spatial rainfall climate variability reasonably well with low rainfall days $(1-10 \mathrm{~mm} /$ days $)$ in almost all zones, heavy rainfall events in western, northern, southeastern hilly and coastal zones and extremely heavy rainfall events in northern coastal zones. An increasing trend of heavy rainfall in central, southern and southeastern parts, a decreasing trend in Iberian Peninsula and a steady trend in other zones are found. Overall, the simulated rainfall climatology was reproduced well for the low and heavy

\footnotetext{
"Corresponding author.
}

How to cite this paper: Dasari, H.P. and Challa, V.S. (2015) A Study of Precipitation Climatology and Its Variability over Europe Using an Advanced Regional Model (WRF). American Journal of Climate Change, 4, 22-39. 
rainfall followed by very heavy and extremely heavy rainfall in Europe and the simulation is better in the Iberian west coast, central northern Europe and Alps Mountains.

\title{
Keywords
}

\author{
Regional Climate, Rainfall, Europe, WRF-ARW, Threat Score
}

\section{Introduction}

Global climate change is an important environmental issue in recent times. The rising concentration of greenhouse gases in the atmosphere due to manmade activities and their potential impact on climate are among the research issues of scientific and policy interest [1]. The increasing rates of fossil fuels consumption, deforestation and other anthropogenic interventions have been attributed to increase the emission of certain greenhouse gases (GHG) in the atmosphere [2] that cause changes in the global climate [3] [4]. The future changes in the temperature and precipitation patterns at global, regional and local scales are important parameters for the assessment of the impact at the eco-system level. Though global climate models (GCMs) provide the basis to understand the immediate consequences of increased GHGs in terms of alteration in atmospheric circulation, energy transport, shifts in temperature and rainfall patterns, and changes in hydrological cycle on a large scale, it is now essential to relate these changes to different regions to understand their impact at regional scale for policy making. To address this, dynamical downscaling of future climate projections by coupling the regional models to global models (GCMs) has been identified to be a thrust area and the related studies have been recognized as regional climate modelling. RCMs have been widely employed to assess the impact of climate change at regional and local scales e.g. [5]-[7] as they can better simulate the land surface and precipitation processes using appropriate parameterizations at high horizontal resolution. Several studies demonstrated the advantages of regional models, with higher spatial and temporal resolution, in regional climate prediction by suitably integrating them with the boundary conditions derived from GCMs [8]-[10] RCMs provide localized, high resolution information, consistent with the large scale climate simulated by GCM forcing [11]. A number of regional models have been developed to study regional climate and to derive necessary inputs to ecosystem models. Some of the popular RCMs include the RegCM [7] [12]-[16] Colorado State University Regional Atmospheric Modelling System (CSU/RAMS) [17], Rossby center's regional atmosphere land climate model [18], IPRC-RegCM [19] the UKMO unified model and the regional model of JMA. Also several regional climate study programs have evolved over different parts of the globe viz., PRUDENCE, CLARIS, SWECLIM, NARCCAP, ENSEMBLES [20]-[24].

The ENSEMBLES project [24] is one of the major efforts to study the regional climate change over Europe. This study involved thirteen different RCMs to inter-compare each individual model with the real atmosphere [25]-[31]. The studies from this project reported the outstanding performance of RCMs and have also addressed the uncertainties in the RCMs and the scope for further improvements [26] [32]. The earlier modelling studies on regional precipitation indicated the need of more observational network especially in areas of complex topography where the RCMs have been found to perform poor. For instance, [26] reported that the RCMs performance is relatively poor over Mediterranean area in comparison to other parts of Europe. Raucher et al. [27] have shown that the usage of high resolution RCMs improves the predictive skills for rainfall with respect to seasons. Though most studies reported that the precipitation is with higher resolution [33], the general consensus is that models better predict the rainfall with increase in resolution. Herrera et al. [34] while analyzing the precipitation from RCMs for Spain region with 0.2 degree gridded data rainfall data found that the model overestimated the frequency of rainfall giving rise to simulated wet and dry spells and under representing the extreme events. Soares et al. [35] validated ENSEMBLE RCM produced rainfall at different time scales (daily to seasonal) for Portugal with high resolution rainfall data sets [33] [36]. In recent times, the Weather Research and Forecasting (WRF) model has been widely used for regional modelling studies due to its accurate numerics, improved dynamics and large range of physics parameterizations [37]. Heikkila et al. [38] used WRF model over the Norway and compared the simulated rainfall with other models. It has been found that the performance of WRF is superior to the ENSEMBLE RCM simulations due to higher horizontal resolution. Similarly, Soares et al. [39] reported that the precipitation simulations using WRF have shown improved skills with high resolution 
ERA-interim data as boundary forcing and it has been found that there is a high intra and inter seasonal variability with high spatial homogeneity of rainfall over Portugal. Daniel et al. [40] evaluated WRF performance at 10 $\mathrm{km}$ resolution forced by ERA-40 re-analysis fields and its sensitivity to eight different combinations of cumulus, microphysics and planetary boundary layer (PBL) parameterization schemes over a topographically complex region in southern Spain (Andalusia), for the period 1990-99. Comparisons with observations at different time scales indicated that WRF simulate realistically the Andalusia climate. Daniel et al. [41] [42] presented the performance of WRF model over Spain, which demonstrated the model's ability to produce increasing/decreasing trends in present climate from 1970-1999 of mean and extreme precipitation events over the region. Hari Prasad et al. [43] [44] studied the regional climate changes over Europe on its extreme temperatures associated with heat and cold waves. Hari Prasad et al. [45] also studied the model predictive capability of cold over central Europe. The above studies with WRF model are limited to few selected regions over Europe and were also limited to past few decades, mainly to understand the model ability in resolving the extreme rainfall events and their interannual variability.

To our knowledge not many regional climate studies are reported at a continental scale over Europe. Variability of regional precipitation over a continental scale is an important issue in climate modelling. In this context, the present study aims to study the application of an advanced regional model WRF to simulate spatial and longterm variability in regional rainfall over Europe a sixty-year period between 1950 and 2010. The simulated regional scale precipitation and its extremities over the study period are compared with the 25-km resolution EOBS [46] precipitation analysis data following the methodology adopted from [43]. The paper is organized in five sections. Section 2 deals with model configuration and data sets used in the study. In section 3 the statistical methods used for evaluation are described. Section 4 provides the results and discussion of rainfall analysis and finally summary and conclusions are presented in Section 5.

\section{Model Design and Datasets Used for This Study}

The advanced high resolution Weather Research Forecasting (WRF-ARW) model developed by NCAR, USA [37] is used in this study. This model uses primitive equations, non-hydrostatic dynamics and terrain following sigma coordinate system. For the present study a double nested domain configuration (domain 1: $75 \mathrm{~km}$, domain 2: $25 \mathrm{~km}$ horizontal resolutions) is selected. The inner domain is two-way interactive with outer domain. The domain configuration is shown in Figure 1(a) and the terrain elevation of the inner study domain is shown in Figure 1(b). The model physics and other details are presented in Table 1. The outer domain covers the entire Europe and parts of Atlantic Ocean and adjacent regions. The inner domain covers the European continent from $32^{\circ} \mathrm{N}$ to $56^{\circ} \mathrm{N}$ and $15^{\circ} \mathrm{W}$ to $25^{\circ} \mathrm{W}$.

The three dimensional atmospheric fields at the initial time and the time varying boundary conditions are taken from the National Centers for Environmental Prediction (NCEP) global analysis fields [47] available at

Table 1. Model details and configuration.

\begin{tabular}{|c|c|}
\hline Model name & NCEP/NCAR ARW \\
\hline Model type & Primitive equation, non-hydrostatic \\
\hline Vertical resolution & 30 sigma levels \\
\hline Horizontal resolution & $25 \mathrm{~km}$ \\
\hline Domain of integration & $\begin{array}{cc}38.5 \mathrm{~W}-30.83 \mathrm{E} & 13.585 \mathrm{~W}-24.8351 \mathrm{E} \\
21.82 \mathrm{~N}-59.75 \mathrm{~N} & 31.7935 \mathrm{~N}-55.7455 \mathrm{~N}\end{array}$ \\
\hline Radiation scheme & $\begin{array}{l}\text { CAM scheme for short wave radiation. } \\
\text { CAM scheme for long wave radiation }\end{array}$ \\
\hline Land-Surface scheme & Thermal diffusion scheme \\
\hline Sea Surface Temperature & Real Sea Surface Temperatures \\
\hline Convection scheme & Grell-Devenyi ensemble scheme \\
\hline PBL scheme & YSU scheme \\
\hline Explicit moisture scheme & WSM 3-class simple ice scheme \\
\hline
\end{tabular}


2.5 degree latitude/longitude resolution and at 6 hour interval. To study the precipitation trends a total of 60 yearly simulations each for one year in the period from 1950 to 2010, are performed. In each simulation the model is integrated continuously for 13 months, starting from 00UTC of 1 May. In the present study only the results from the inner $25 \mathrm{~km}$ resolution nest domain are analyzed. Model simulated daily accumulated rainfall is used for the analysis. The first one month of each simulation is neglected from analysis due to model spin up time. The model results for the 60-year period (1950 to 2010) are compared with E-OBS V7.0 [46] daily accumulated rainfall observations, available at 0.25 degree. Spatial statistics between observations and model produced rainfall are computed at different time scales. Five different timescales (daily, 5-day, 15-day, monthly and seasonal) are chosen to study the accumulated rainfall variation in these scales for the period of study. The domain of interest covering the $2^{\text {nd }}$ domain is divided in to 15 zones, based on topographic variations and the area averaged daily accumulated rainfalls are computed for both model and observations and used in the extreme events analysis.

\section{Statistical Method Used for This Study}

Murphy and Winkler [48] gave a general framework for model evaluation. To assess the long term performance several statistical indices are estimated. The statistical indices used in the present analysis are adopted from a number of earlier model performance studies [49]-[52]. The statistical indices used in the study are Pearson correlation coefficient (COR), Normalized Bias (NBIAS), Normalized Mean Absolute Error (NMAE) and Normalized Standard Deviation (NSTDEV) as given below.

$$
\begin{gathered}
\mathrm{COR}=\frac{\sum_{i=1}^{n}\left(f_{i}-\bar{f}\right)\left(o_{i}-\bar{o}\right)}{\sqrt{\sum_{i=1}^{n}\left(f_{i}-\bar{f}\right)^{2}} \sqrt{\sum_{i=1}^{n}\left(o_{i}-\bar{o}\right)^{2}}} \\
\mathrm{BIAS}=\frac{1}{n} \sum_{i=1}^{n}\left(f_{i}-o_{i}\right)=\bar{f}-\bar{o} \\
\mathrm{STDEV}=\sqrt{S_{f}^{2}+S_{o}^{2}-2 S_{f} S_{o} r_{f o}} \\
\text { MAE }=\frac{1}{n} \sum_{i=1}^{n}\left|f_{i}-o_{i}\right| \\
\text { RANGE }=\left(o_{\text {max }, i=1, n}-o_{\text {min }, i=1, n}\right)
\end{gathered}
$$

From Equation (2) to (5), the normalized values for each statistical indices can be obtained by the following formulas

$$
\begin{aligned}
& \text { NBIAS }=\left(\frac{\text { BIAS }}{\text { RANGE }}\right) \times 100 \\
& \text { NSTDEV }=\left(\frac{\text { STDEV }}{\text { RANGE }}\right) \times 100 \\
& \text { NMAE }=\left(\frac{\text { MAE }}{\text { RANGE }}\right) \times 100
\end{aligned}
$$

where $O_{i}$ is an observable variable, $f_{i}$ is a modeled variable, over bar represents average over all the data, " $n$ " is the total number of locations that predicted data are compared against observations. Bias is a measure of mean error for a continuous variable, $\mathrm{SD}$ is the standard deviation of the error $(f-o)$, where $S_{f}$ is the standard deviation in forecasts, $S_{o}$ is the standard deviation in observations and $r_{f o}$, the correlation between the forecasts and observations. Specifically, MAE is less influenced by large errors and also does not depend on the mean error. The normalized values of BIAS, STDEV and MAE are often expressed in percentages. The NBIAS is a measure of over estimation (+ve values) or under estimation (-ve values) of a variable. Similarly NSTDEV and NMAE are also expressed in percentages with smaller values indicating better agreement between observed and modelled 
values. These statistical indices are computed at different forecast periods of accumulated rainfalls (1-day, 5-day, 15-day, monthly and seasonal).

\section{Results and Discussions}

The potential of WRF model for simulating the regional precipitation over Europe is assessed in a retrospective way. The anlaysis is made to understand the variations in accumulated precipitation at different time scales i.e., daily, 5-day, 15-day, monthly and seasonal and also rainfall episodes of heavy (1 $-10 \mathrm{~mm} /$ day $)$ to extremely heavy rainfall ( $>25 \mathrm{~mm} /$ day) events over Europe. Simulated rainfall (hereafter referred as Model) on these time scales is compared with actual spatial rainfall estimates of Europe from E-OBS (hereafter referred as OBS). The precipitation climate is generated as 60 years mean of yearly accumulated rainfall (Figure 2). The simulated 60year mean rainfall is found to match with the observed climatology over different parts of Europe. The spatial pattern from the OBS indicates that the annual rainfall ranges from $750-1500 \mathrm{~mm}$ in central parts of the Europe to $250-750 \mathrm{~mm}$ over Iberian Peninsula, eastern and northeastern Europe. The highest annual rainfall (1500 $2000 \mathrm{~mm} /$ year) is found in few isolated areas like north of Portugal and Alps mountains. The spatial patterns of rainfall are well simulated all over Europe except for a slight underestimation (by $\sim 30 \%$ ) over Alps Mountains. Over central Europe and southern coastal parts of Portugal the model climatology shows nearly similar rainfall pattern but with an underestimation of about 100 to $200 \mathrm{~mm}$. Model rainfall climate over Eastern Europe is in agreement with the observed climate. It is noted that the correlations (obtained at $95 \%$ significance level) between model and observations (Figures 3(a)-(e)) increase with increase in time scale of accumulated rainfall.
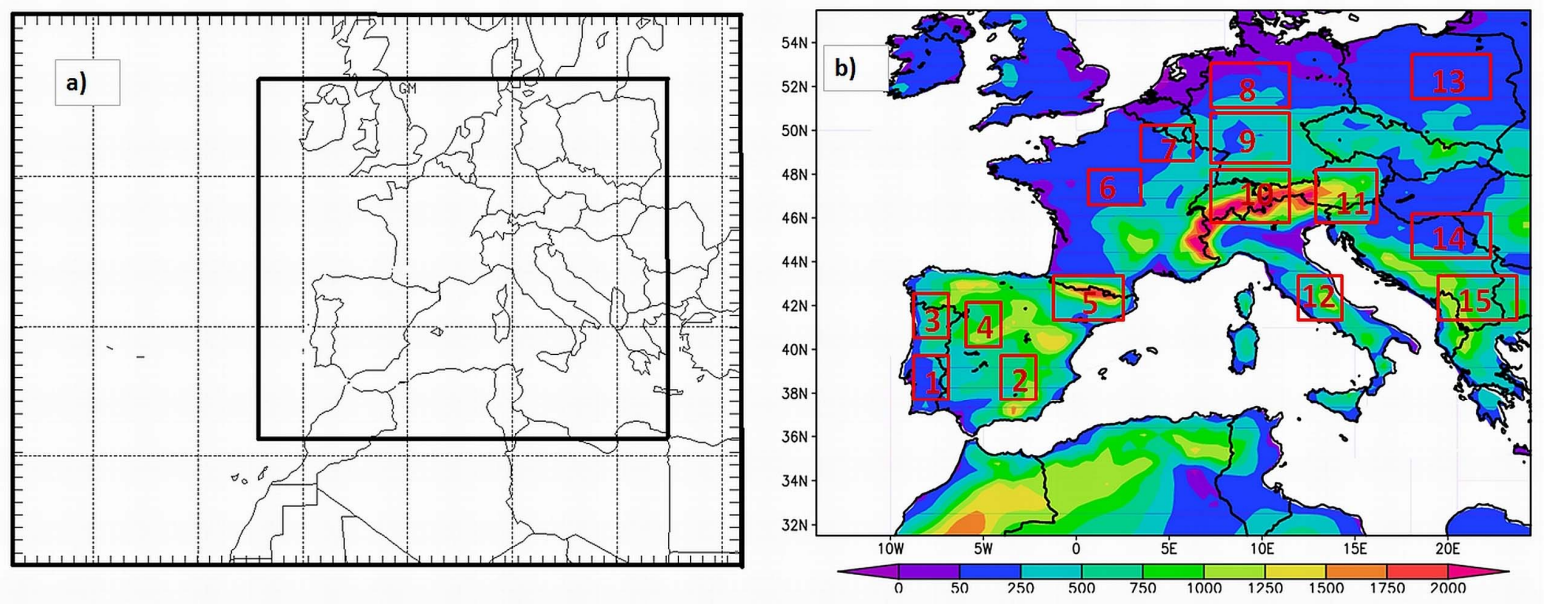

Figure 1. (a) Model domains used for this study; (b) Topography along with chosen region.
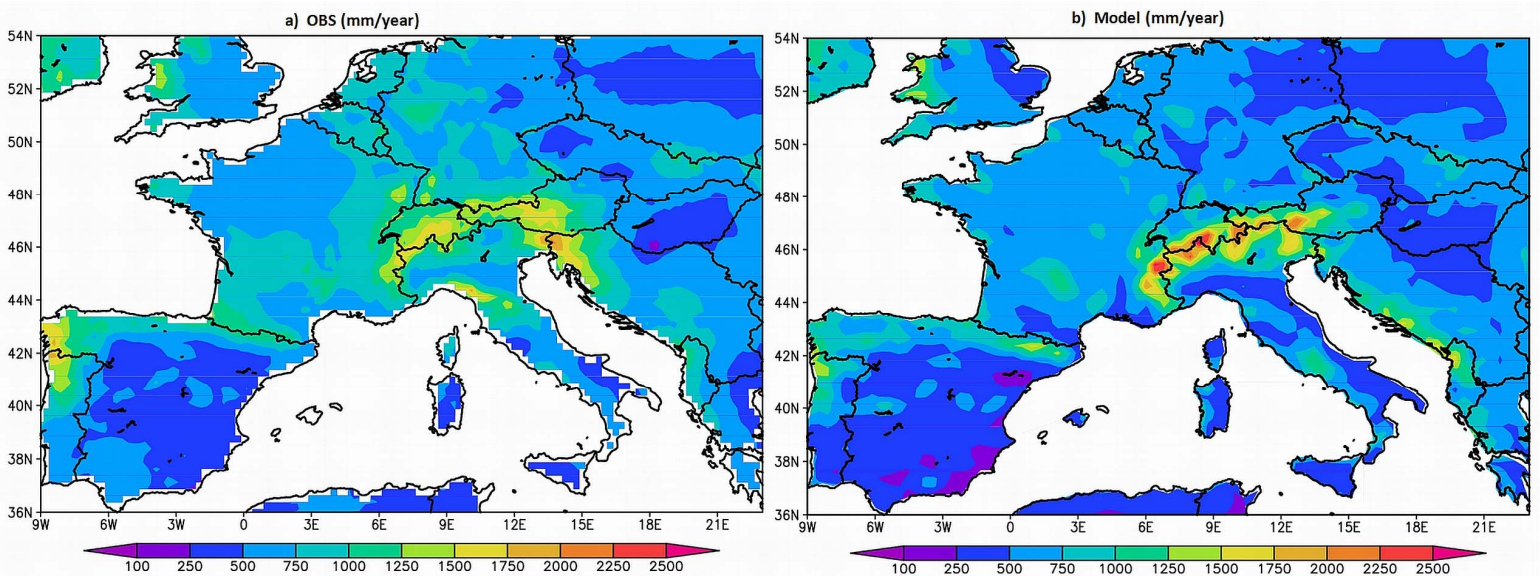

Figure 2. 60-year mean rainfall climatology (mm/year) from (a) observations and (b) model. 

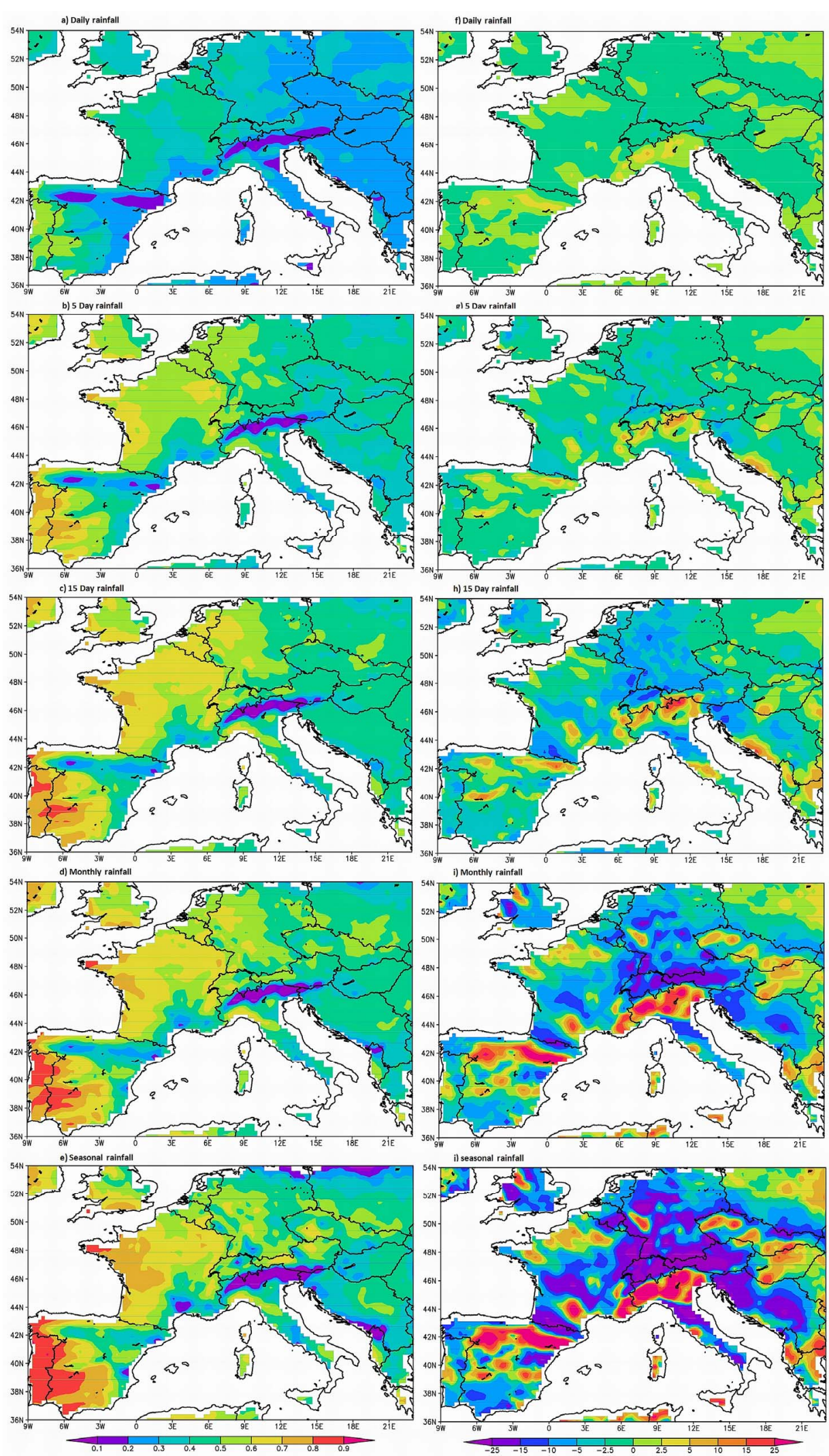

Figure 3. Grid point statistics between OBS and model for different accumulated rainfalls (left panel correlation and right panel is for normalized BIAS). 
Also, the improvements in rainfall correlations over different timescale are predominantly seen over Iberian Peninsula, northwest and Western Europe. The correlations for rainfall over entire Europe improved from 1-day scale $(0.2-0.7)$ to 5 -day scale $(0.4-0.8)$ and further improved to 15 -day and seasonal scales $(0.4-0.9)$ (Figures 3(a)-(e)). The correlations are appreciable at time scale of 15 days and above. The low correlations at short time scales ( $<5$ days) indicates the inability of regional climate model to resolve the short-time mesoscale phenomena and the associated convection at moderate resolution $(25 \mathrm{~km})$ used in the study. In all the above time scales relatively high correlation is found over Portugal/west Iberian region and west-central Europe and low correlations are found over Alps region and Eastern Europe. The poor correlations over these mountainous regions could be due to inadequate model resolution $(25 \mathrm{~km})$ to resolve the complex terrain and the orographic precipitation processes. The inherent bias in gridded rainfall analysis due to insufficient observation density could be another reason for low correlations of simulated rainfall over the hilly areas.

It is seen that the normalized bias in rainfall grows with increasing time scale (Figures 3(f)-(j)) from 1 day to a season, for entire Europe. The errors are in the range of $-2.5 \%$ to $5 \%$ for 1 day accumulated rainfall, the errors increase to $-5 \%-10 \%$ for 5 days accumulated rainfall and further to $-25 \%-25 \%$ for 15 days to seasonal accumulated rainfall. The errors are negative, indicating underestimation of rainfall lover central Europe and positive over western and eastern parts implying over estimation in these areas. On 1-day and 5-day time scales the rainfall is overestimated by $2.5 \%-10 \%$, over isolated areas (Figure 3(f), Figure 3(g)) especially in high altitude regions located in the central Europe and western parts. For 15-day accumulated rainfall, the errors increased to $-10 \%-15 \%$ over hilly regions and to $25 \%$ over central European plateau. On monthly and seasonal time scale (Figures 3(h)-(j)), the rainfall errors increased to $\geq 25 \%$ with considerable overestimation over mountainous regions and to $\leq 25 \%$ with underestimation in foothills of mountains. The actual errors in rainfall quantified by NMAE vary as $5 \%$ for the daily rainfall, about $7.5 \%$ for 5 -day accumulated rainfall (Figure 4(a), Figure 4(b)). The Iberian Peninsula has low NMAE values whereas mountainous regions have relatively high NMAE. On an average the mean absolute errors over the entire Europe are found to be $15 \%$, though the errors increase with increasing time scale. Correspondingly the NSTDEV between model and observed rainfall (Figure 4(f), Figure $4(\mathrm{~g}))$ are seen to grow with increasing time scale $(7.5 \%$ on 1 day, $10 \%$ on 5 days, $10 \%$ to $15 \%$ on 15 days and $20 \%$ to $>25 \%$ on seasonal scale). The errors are far higher over central Europe ( $\geq 25 \%)$ and $15 \%$ to $25 \%$ over Eastern Europe for 15 days to monthly accumulated rainfall amounts (Figures 4(h)-(j)). In general the NSTDEV is lower over Iberian Peninsula region and high over mountain regions. In central Europe a similar error of about $10 \%$ - $15 \%$ range are found and errors increased from $7.5 \%$ to $20 \%$ from 1 day accumulated rainfall to seasonal accumulated rainfall.

The frequency of wet days with respect to occurrence of low rainfall $(>1 \mathrm{~mm} /$ day), heavy rainfall $(>10$ $\mathrm{mm} /$ day) and extremely heavy rainfall days ( $>20 \mathrm{~mm} /$ day) during the 60 -year period from observations and model is presented in Figure 5. As expected the frequency decreases from $1 \mathrm{~mm} /$ day to $>20 \mathrm{~mm} /$ day over various parts of Europe except the northern Portugal and Alps region where high frequency of heavy rainfall events is simulated as in observation for both the categories of $10 \mathrm{~mm} /$ day and $20 \mathrm{~mm} /$ day. From the OBS it is noted that the mean number of wet days (Figure 5(a)) with $1 \mathrm{~mm}$ /day ranges from 50 to 200 days/year with large spatial variability and highest wet days over northwestern, central Europe and over Alps. Over southern parts of Iberian Peninsula region the number of wet days is found less than 75 days/year. The number of wet days increased to $125-150$ days/year over northern Iberia. The number of wet days is simulated as $100-150$ days/year in northwestern, central and 175 days/year over Alps region. In the Eastern Europe the simulated rainy days are about 75 in good agreement with observations. While the rainfall distributions are well captured by the model over (Figure 5(b)) Iberian Peninsula, rainy days are underestimated by about $15-20$ days/year in other parts of Europe. The mean number of heavy rainy day distribution over Europe has large spatial variation compared to the frequency of both wet days and extremely heavy rainy day's distribution. By and large the model reproduced the frequency distribution of rainy days in good agreement with the observations. Over northern Portugal and adjacent parts of the Iberian region the frequency is about 45 days/year for heavy rainfall days, 24 days/year for extremely heavy rainfall days. In southern part of Iberian Peninsula the frequency varies as 15 days/year for heavy rainfall days and 4 days/year for extremely heavy rainfall days in agreement with OBS. Over central Europe and some parts of Eastern Europe and adjoining coastal regions the heavy rainfall days are about 30 - 35 days/year and extremely heavy rainy days are about 4 days/year. These features are well represented by the model in good agreement with OBS. The relatively high number of days for heavy rainy days ( 50 days/year) and extremely heavy rainy days ( 30 days/year) over Alps region are also well produced by the model. 

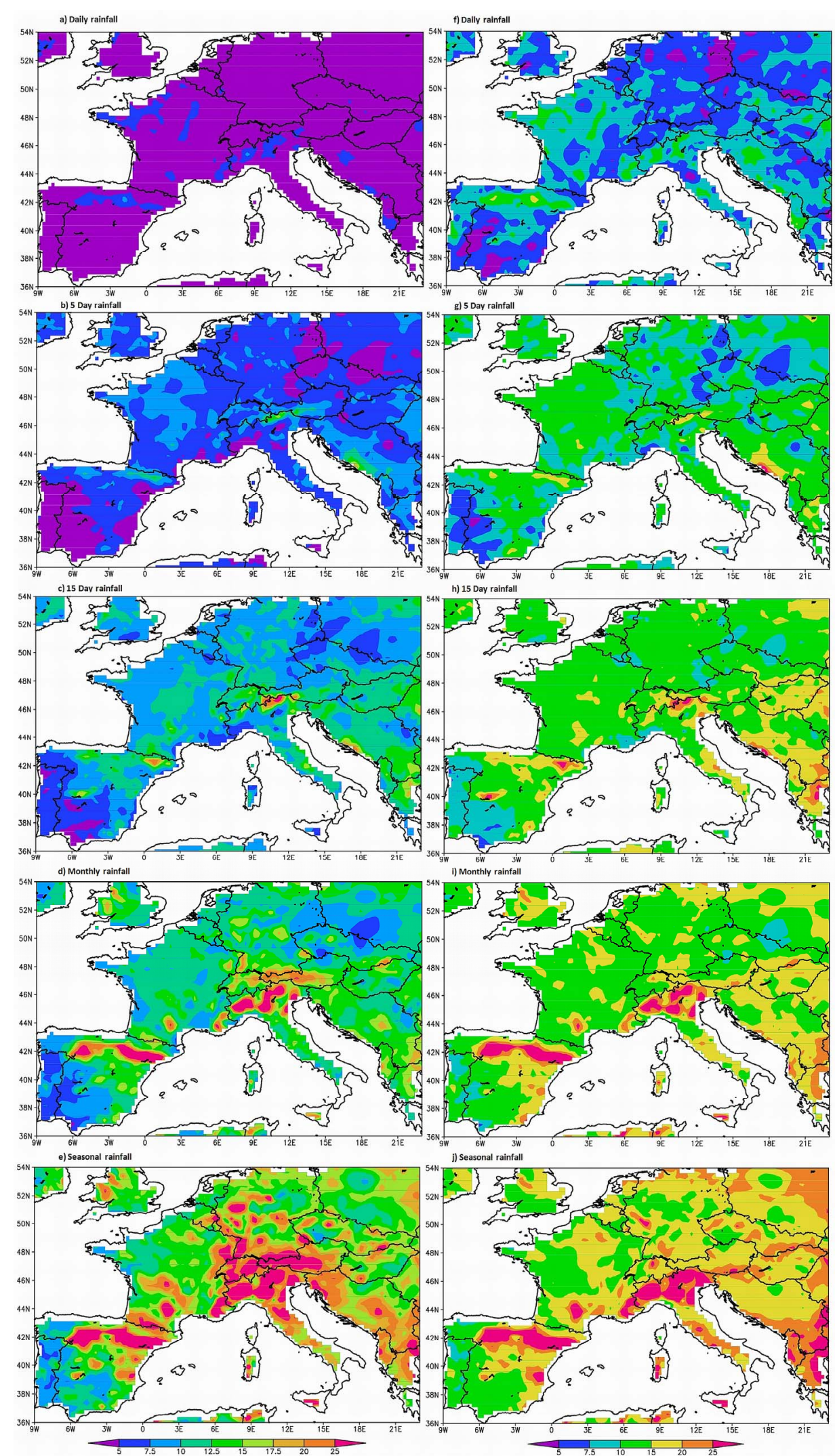

Figure 4. Same as Figure 3 but (left panel is for NMAE and right panel is for NSTDEV). 

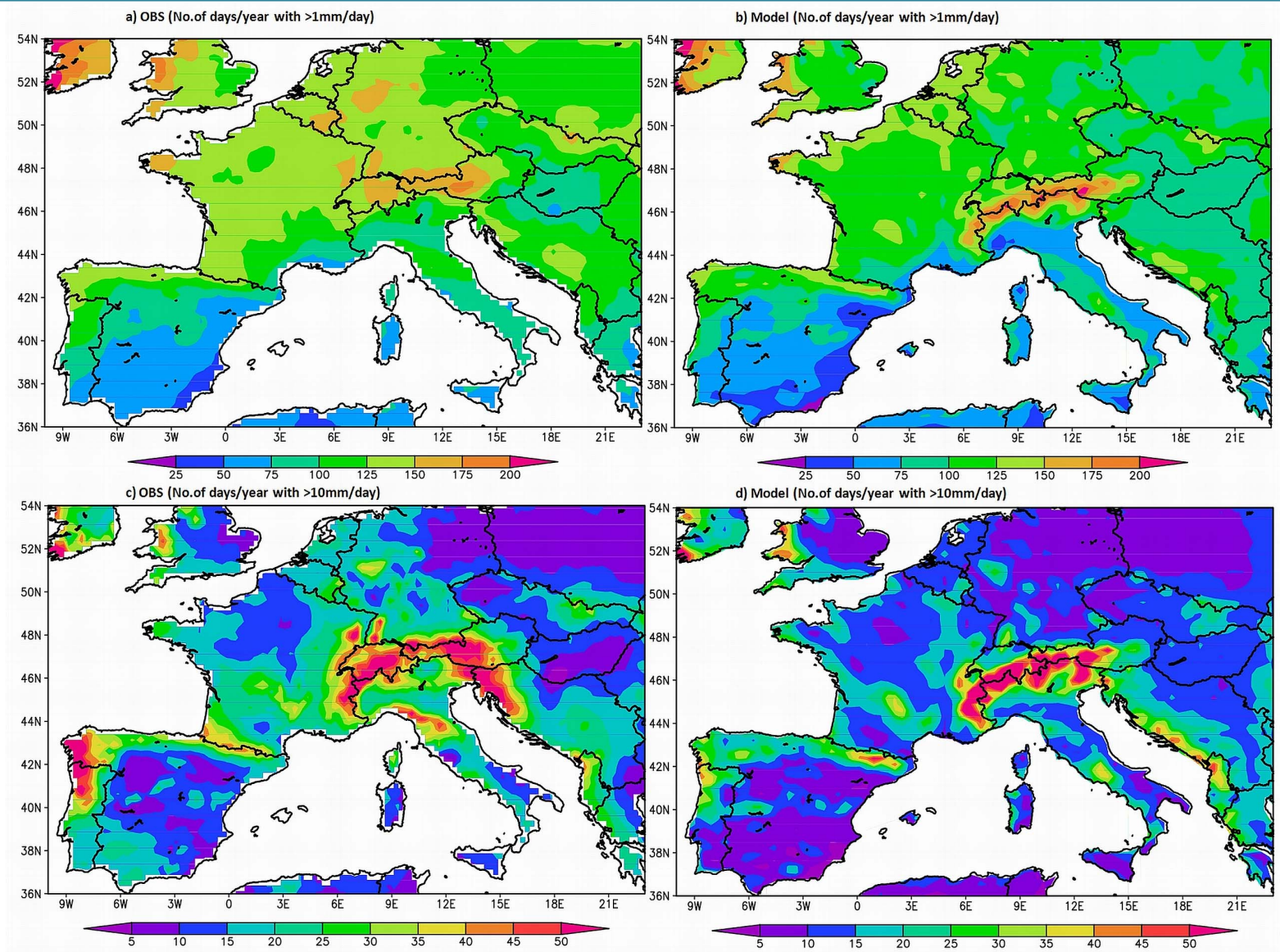

d) Model (No.of days/year with $>10 \mathrm{~mm} /$ day)

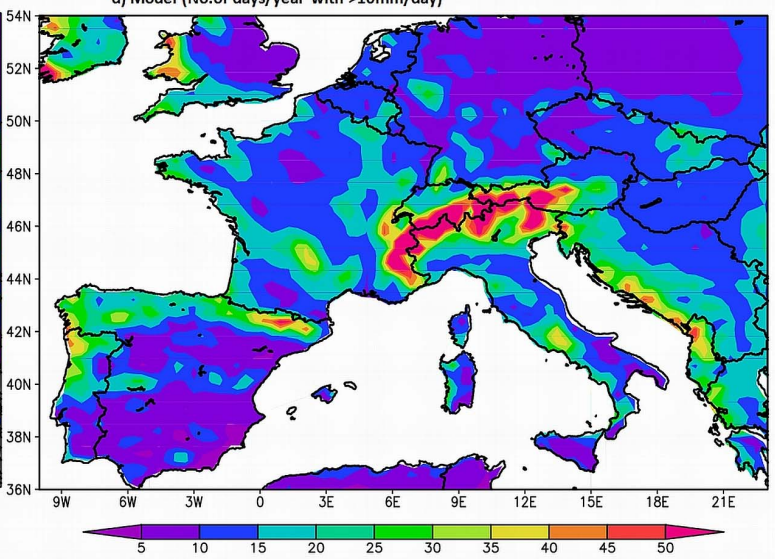

e) OBS (No.of days/year with >20mm/day)

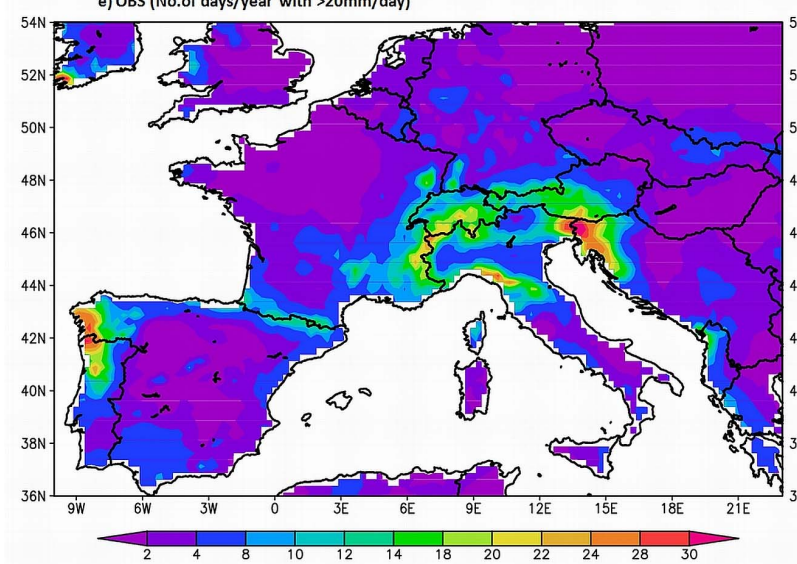

f) Model (No.of days/year with $>20 \mathrm{~mm} /$ day)

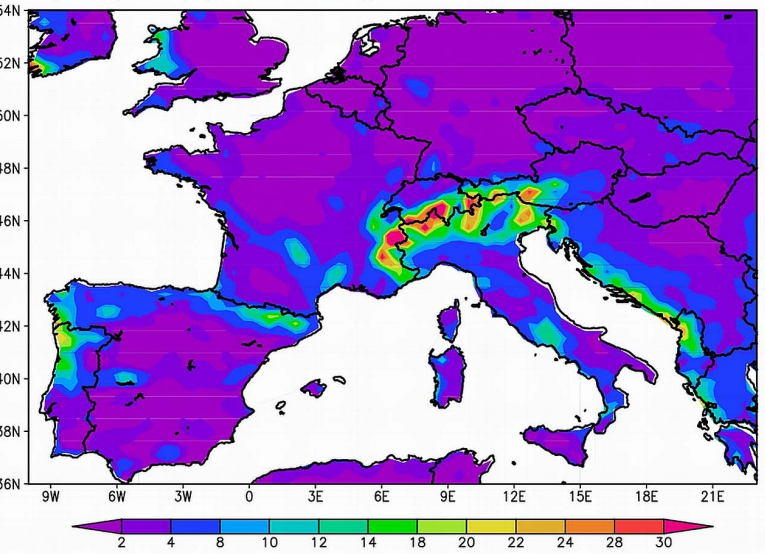

Figure 5. Mean number of wet days with different rainfall amounts for both observations and model values.

Next we analyze the mode of highest rainfall occurrence on daily and 5-day time scales in the 60-year period (Figure 6). The OBS shows that in most parts of the Iberian Peninsula and central and Eastern Europe a highest rainfall of $>100 \mathrm{~mm}$ /day occurs and in some parts over Alps region about $125-150 \mathrm{~mm}$ /day also occurs in agreement with observations. However, the simulated high amount of rainfalls over coastal Mediterranean region is not realistic. Similarly, the 5-day mode of highest rainfall is well produced by model as in OBS with high rainfall amounts north of Portugal, north of Italy and adjoining regions. In other parts of Europe less probability for high rainfall on 5-day mode is simulated as in good agreement with observations.

The model performance is examined for mean number of consecutive dry (without rain) and wet days (rain $\geq$ $1 \mathrm{~mm} /$ day) during entire period (Figure 7). Model could reproduce the observed mean number of consecutive 

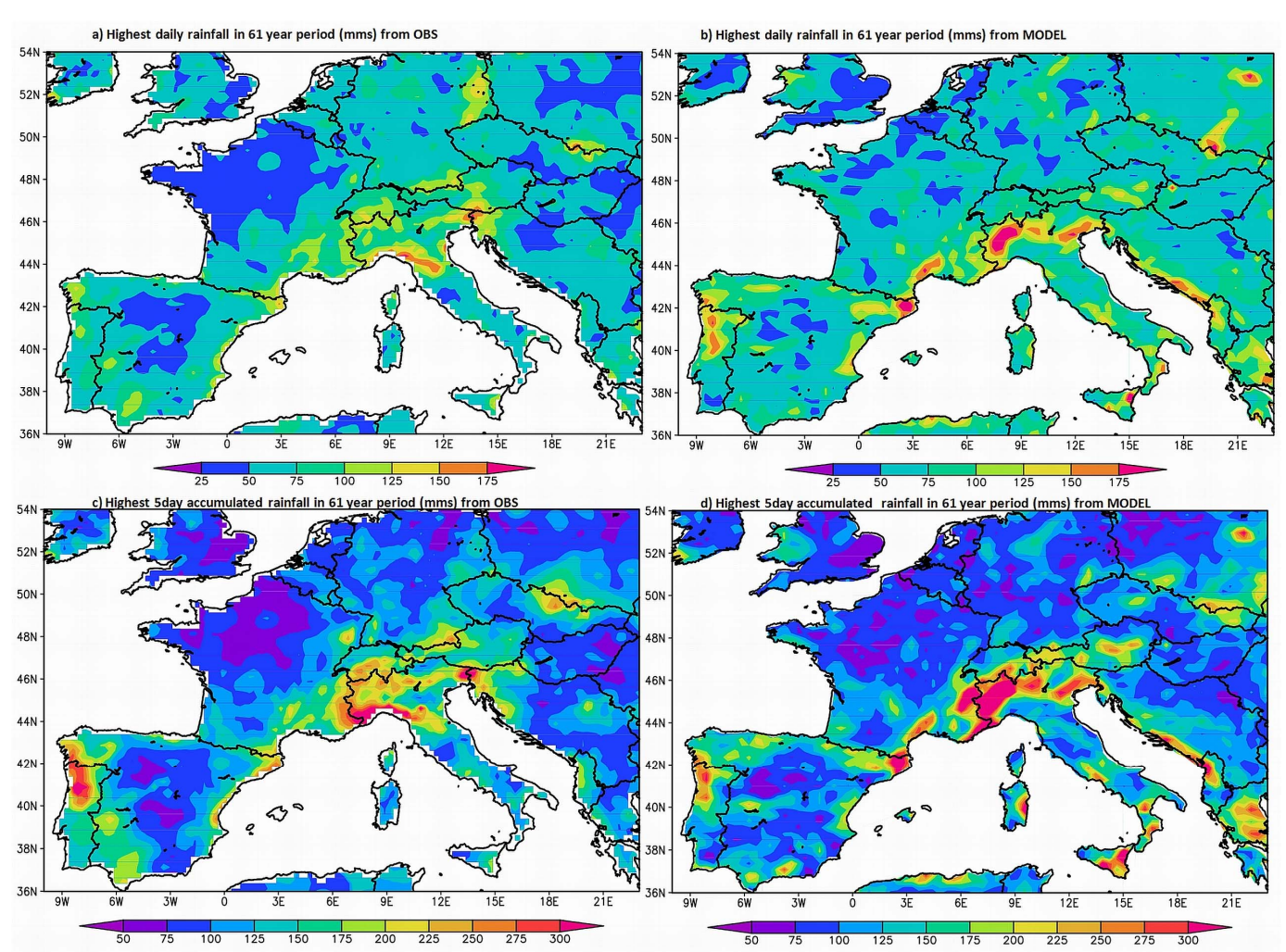

Figure 6. Highest amount of rainfall collected at every grid point in 60 -year period.
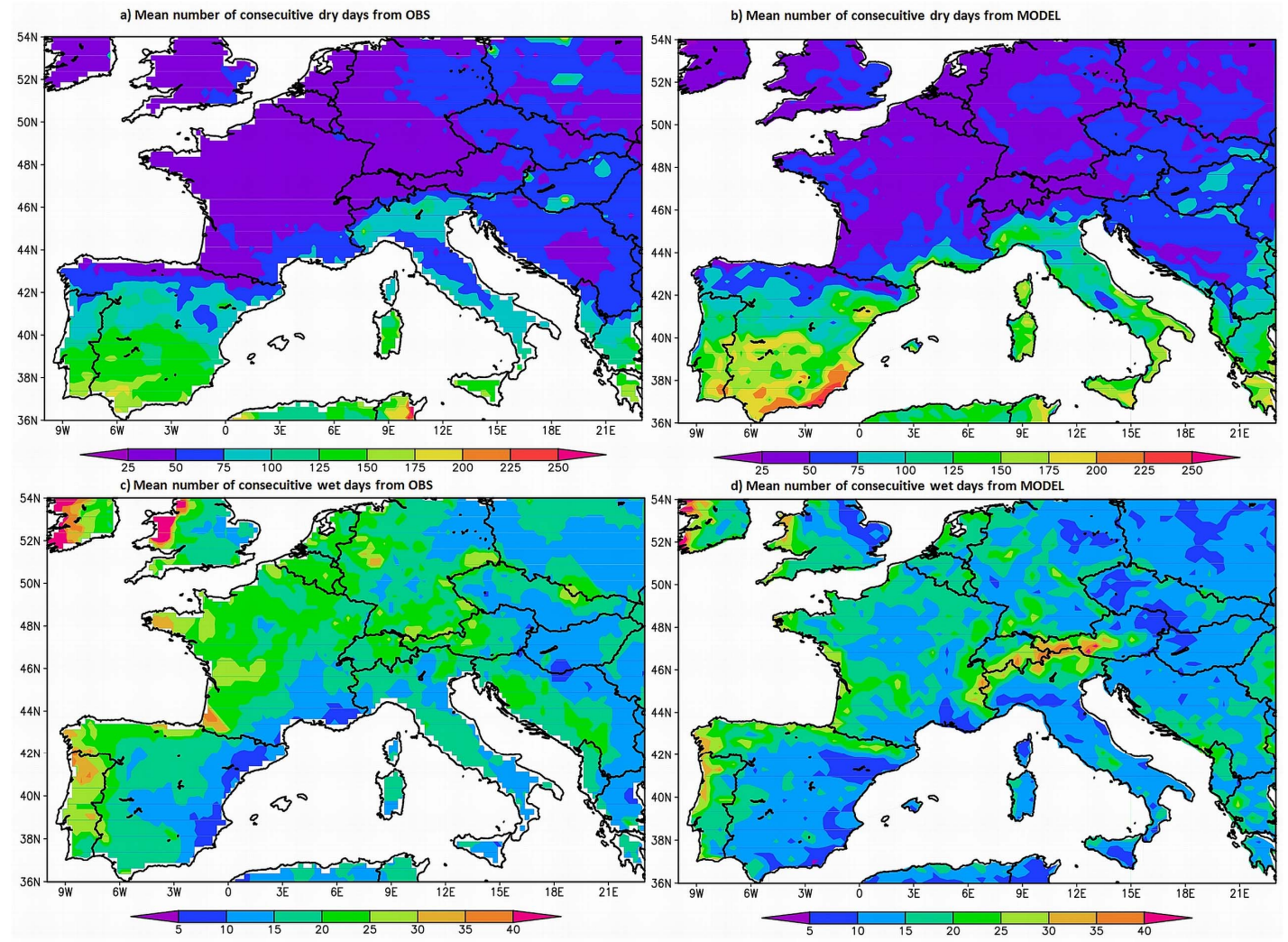

Figure 7. Mean number of consecutive dry days (no rainfall days) and consecutive wet days ( $>1 \mathrm{~mm} /$ day) in 60 -year period. 
dry days (Figure 7(a), Figure 7(b)) and consecutive wet days (Figure 7(c), Figure 7(d)) reasonably well with slight variations in few areas. Over southern Iberian Peninsula the model over estimated the number of consecutive dry days (200 days) in comparison to OBS (150 days). On the contrary the mean number of consecutive wet days is low over southern Iberian Peninsula (about 10 days/year) in OBS and about 20 days/year in simulation. In other parts of Europe simulated mean consecutive dry and wet days are in good agreement with corresponding estimates from OBS. Over other parts of the Europe the model shows relatively less number of consecutive wet days (about 5 days/year) as compared to OBS. These results suggest that the model performed reasonably well for the simulation of rainfall climatology in terms of high correlations and lower NBIAS, NMAE and NSTDEV indicating good skill of the model in reproducing the rainfall on different time scales. The most significant result is that the model produced fairly good statistics for 1-day to 5-day accumulated rainfall amounts and relatively poor statistics for 15 days to seasonal scale rainfall amounts during 60 -year period. The spatial distribution of mean number of rainy days, heavy rainfall days and extremely heavy rainfall days are in good agreement with observations. The model is able to capture the maximum mean number of consecutive dry days and consecutive wet days in reasonable agreement with observations.

To examine the spatial variations associated with the number heavy rainfall events, very heavy rainfall and extremely heavy rainfall events, we considered 15 zones based on the topography (Figure 1(b)). Zones $6-8,13$ - 14 are located in the northern and western Europe with moderate altitude of $\leq 250 \mathrm{~m}$ above mean sea level (AMSL), zones 2 - 5 are located in Iberian Peninsula with mean altitude of 250 to $1000 \mathrm{~m}$ AMSL, zones 10, 11 in the high altitude ( $\geq 1500 \mathrm{~m}$ AMSL) Alps mountain region, zone 12 with moderate altitude and located in the Italian peninsula. The area averaged rainfall from each of the 15 zones for each day is computed from model outputs and observations and then number of heavy rainfall, very heavy rainfall and extremely heavy rainfall days are computed for each year from both model rainfall and observations.

The statistics for number of rainy days i.e. more than $1 \mathrm{~mm} /$ day averaged over each zone is computed from simulation and observations and presented in Figure 8. Note that the correlations are obtained at minimum $80 \%$ significance level. Good correlations between observed and modeled number of rainy days are obtained in most of the zones except zone 15 which has a correlation of 0.3 . The highest correlations $(0.5$ to 0.8$)$ are obtained in zones $1,3,4,7-10,14$ followed by relatively low correlations $(\sim 0.3-0.4)$ in the remaining zones. Correspondingly the NBIAS, NMAE values are very low $(-2 \%$ to $+2 \%, 5 \%)$ in most of the zones which shows the model performed well with a NSTDEV of less than $10 \%$ in producing the frequency of rainy days in each year.

Next, to examine the zonal variability of rainfall under different categories during the period 1950-2010, we computed area averaged daily rainfall events from each zone as well as the number of events per each year from both observations and model. The number of events with respect to heavy rainfall $(1-10 \mathrm{~mm} /$ day $)$, very heavy rainfall (10 - $20 \mathrm{~mm} /$ day) and extremely heavy rainfall (more than $20 \mathrm{~mm} /$ day) are presented in Figures 9(a)-(c) from both observations and model. It is seen that the low rainfall days $(1-10 \mathrm{~mm} /$ days $)$ are well simulated by the model in almost all zones, except for a slight overestimation in zones $3-5$. The heavy rainfall events are simulated relatively less (Figure 9(a)) in the zones 2, 4, 5, 11, 12, 14 in comparison to zones 1, 6, 7, 10, 13, 15. In most zones model underestimates the number of extreme events though the trends are well simulated. In the zones 13 and 15 the model shows less number of extreme rainfall events with lesser significance. In the zones 1 ,

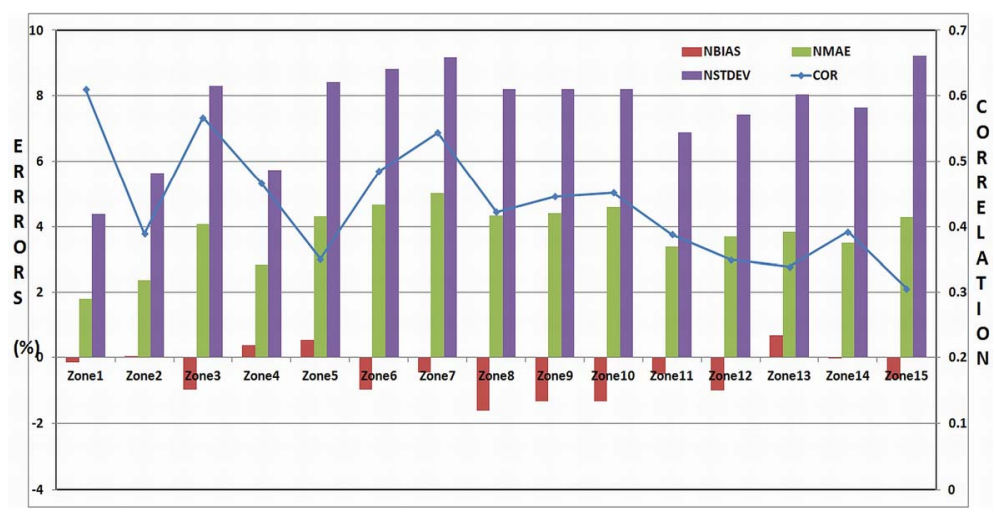

Figure 8. Zone wise statistics for rainfall days (more than $1 \mathrm{~mm} /$ day) for the 60 -year period. 


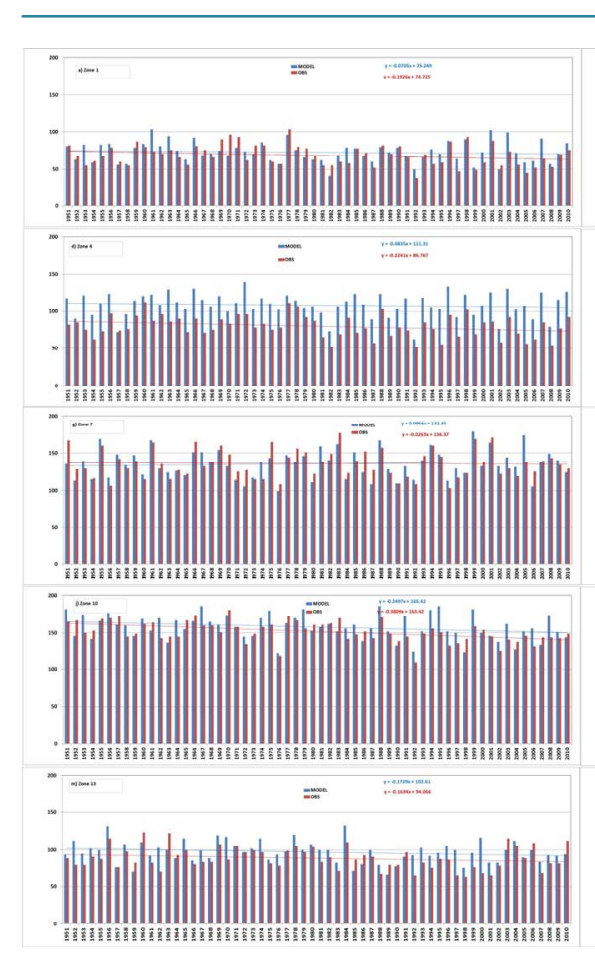

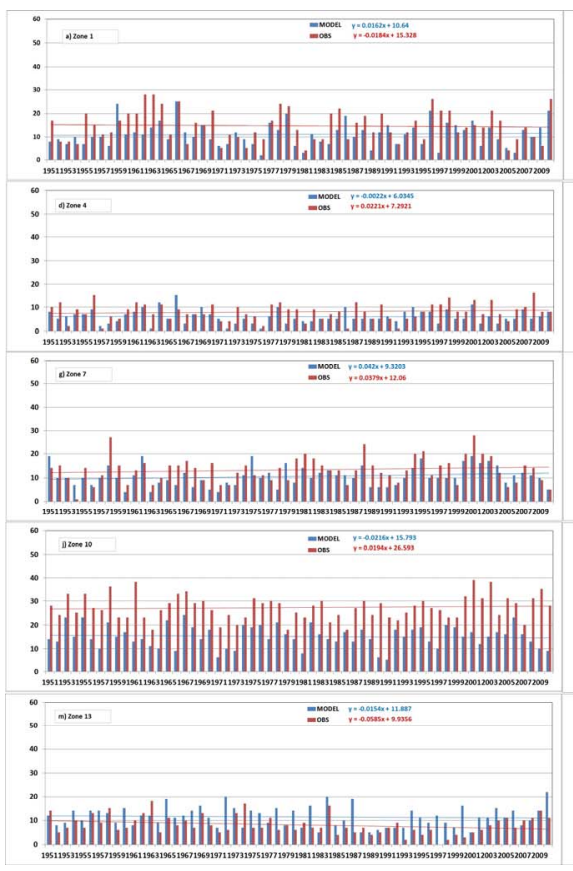

Nomit

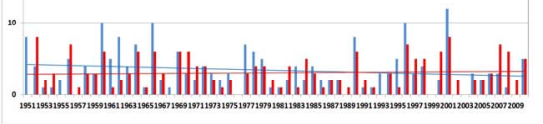
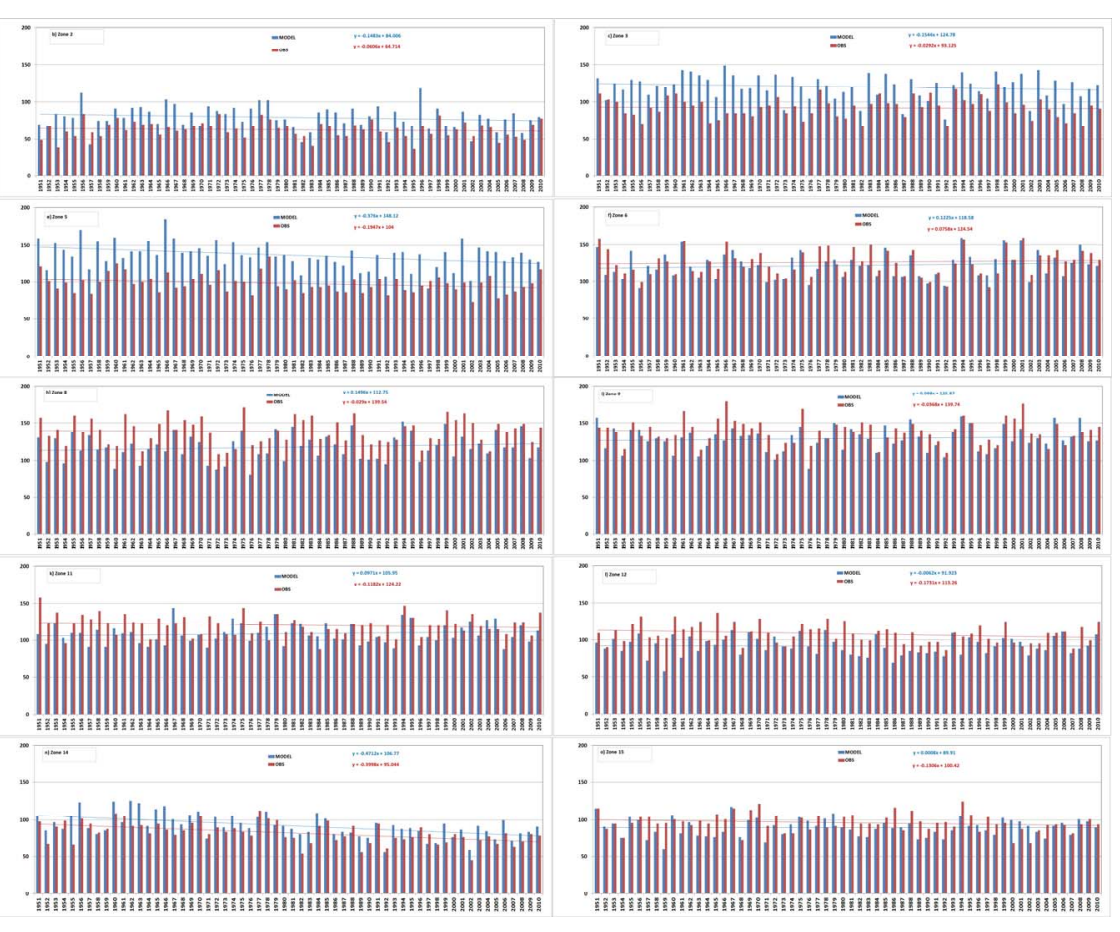

(a)
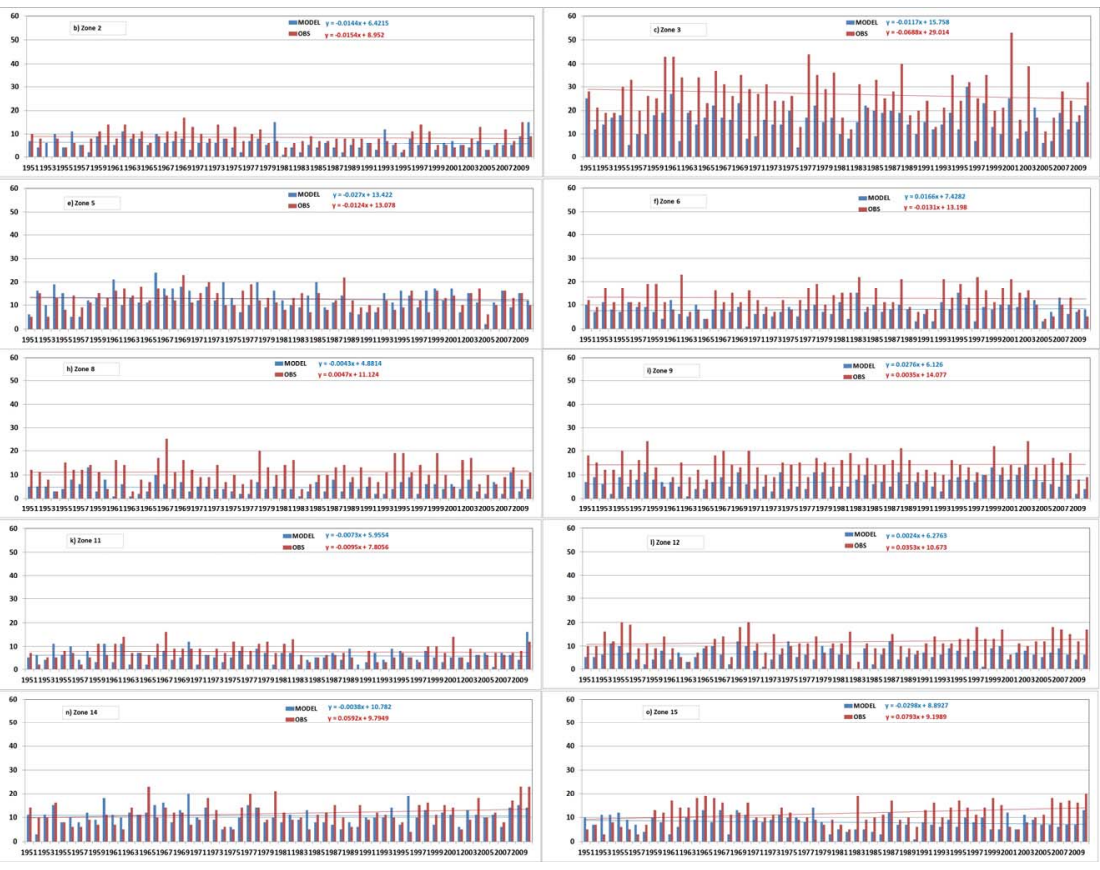

(b)

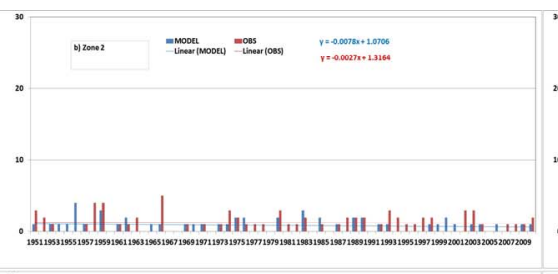




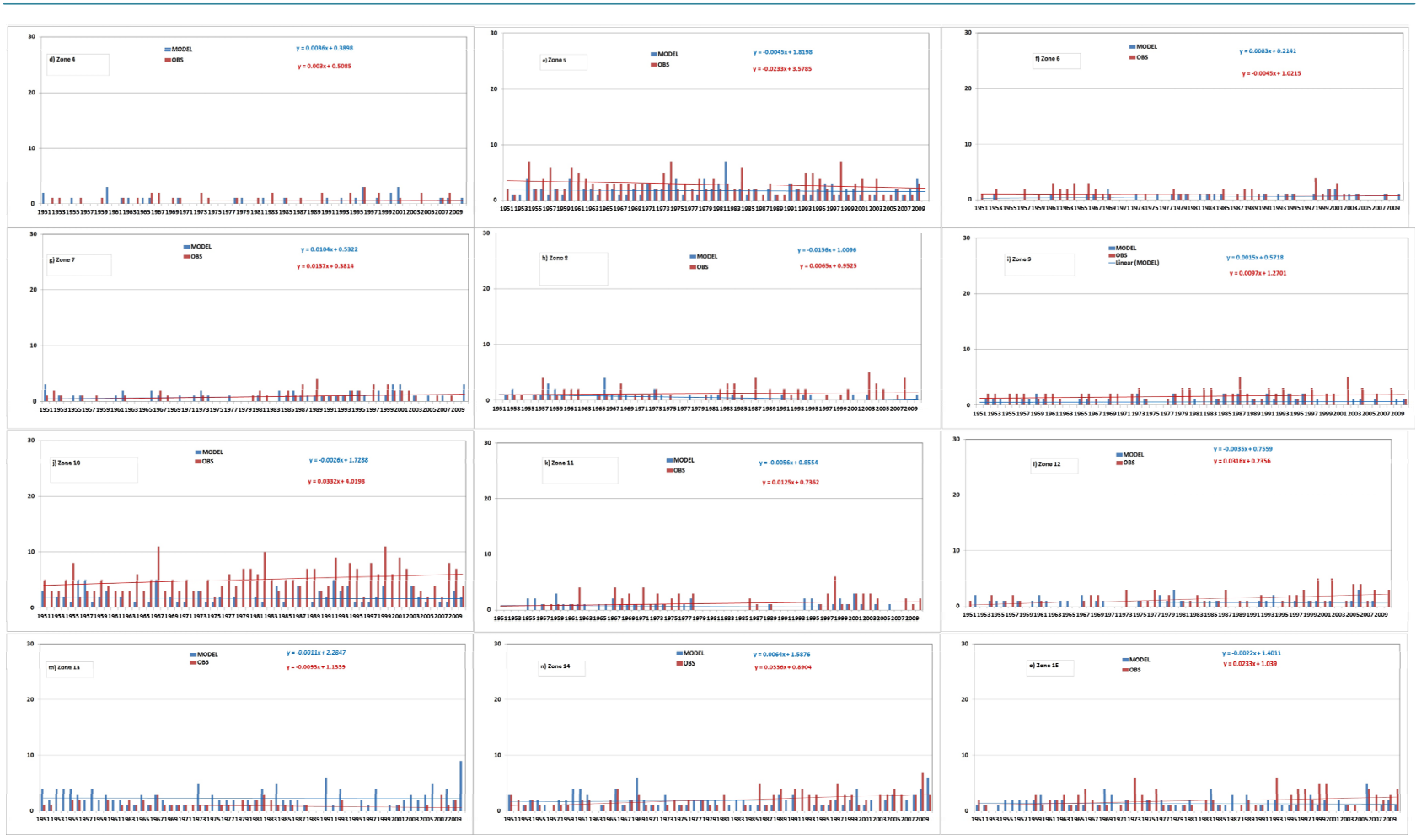

(c)

Figure 9. (a)-(c) Number of rainy days for each zone for each year with (a) $1-10 \mathrm{~mm} /$ day during 60 years; (b) 10 - $20 \mathrm{~mm} / \mathrm{day}$ during 60 years; (c) $>20 \mathrm{~mm} /$ day during 60 -year period for both model and observations.

$3,6,7,8$ and 9 no specific trend is noticed. The same pattern as mentioned above is also seen in observations for number of heavy rain fall events. The correlation between (Figure 10) simulated and observed number of heavy rainfall events is more than 0.6 in most of the zones. The lowest correlations are found in zones $11,15(0.3)$, and highest correlations (0.75) in zones 6 and 7. From Figure 9(a), a decreasing trend of low and moderate rainfall $(1-10 \mathrm{~mm} /$ day) events are seen in almost all zones in agreement with observation trends. Specifically the decreasing trend of low rainfall is found in the zones $3,5,7,10-15$.

The number of heavy rainfall events over most zones is constant (Figure 9(b)) except in zones 3, 7, 10, 12 and 15. In zone 3 a decreasing trend of heavy rainfall events is noted. In zones 7, 10, 12 and 15 an increasing trend is noticed at a significance level of $85 \%$. The increasing trend of heavy rainfall events in these zones is responsible for increasing amount of annual rainfall in the respective zones. In zone 3, the number of very heavy rainfall events is significantly less and found to decrease with time. In other zones no specific increasing or decreasing trends with significance are noted. The correlation between the number of very heavy rainfall events between observations and model is not high as heavy rainfall events. The lowest correlation of 0.1 is found in zone 15 and the highest (0.59) is found in zone 9. The extremely heavy rainfall events are found to slightly increase in the zones 10,12,14 and 15 (Figure 9(c)) where as a decreasing trend is found in zones 3, 5. In other zones no specific trends could be identified. Though the extreme rainfall events are in increasing trend in zones $10,12,14,15$ the trend is not very significant. The rainfall analysis shows zone 3 receives the highest rainfall with an annual average of $2000 \mathrm{~mm}$. However, the number of extremely heavy rainfall events in this zone is found to decrease significantly which indicates a trend of declining rainfall leading to arid/semi-arid climate. The correlations between simulated and observed extremely heavy rainfall events over the 60-year period are relatively low (Figure 10) for the number of heavy to very heavy rainfall events with correlations ranging from -0.05 to 0.56 and the lowest is noticed over zone 13 and highest over zone 1 . The poor correlation values for zones $3,4,8,9,10,12,13,14$ indicate that the model performance is relatively poor for extreme heavy rainfall events in the respective zones. To quantify the model performance for different categories of rainfall threat scores have been computed for heavy, very heavy and extremely heavy rainfall events and compared with corresponding estimates from observations. This permits us to understand the model ability to simulate each ob- 
served category of rainfall. The threat scores (Figure 11) indicate that the model is able to predict around $40 \%$ to $60 \%$ of number of observed heavy rainfall events, 10 to $25 \%$ of observed very heavy rainfall events and about $20 \%$ of extremely heavy rainfall events. The highest threat score values for heavy rainfall are noticed in zones 3 , $6,7,8,9,10$ and 11 with $>50 \%$ accuracy whereas in all other zones the threat scores are below $40 \%$ accuracy. While zone 1 and zone 3 have been found with high threat scores for very heavy rain fall and extremely heavy rainfall categories $(25 \%$ and $19 \%$ for zone 1$)$ and $(22 \%$ and $18 \%$ for zone 3$)$, all the remaining zones are found to have threat scores less than $20 \%$ and $10 \%$ for the above categories respectively. The threat scores clearly indicate that the model is able to simulate the number of heavy rainfall events with a probability of about $50 \%$ and fails to produce the occurrence of very heavy rainfall events $(10 \%-25 \%$ probability) and extremely heavy rainfall events (about 10\% - 15\% probability). Overall, the long term rainfall climatology is well simulated for the categories of heavy rainfall followed by very heavy and extremely heavy rainfall in Europe and the simulation is better for zones 1, 3, 7 and 10 located in the Iberian west coast, central northern Europe and Alps mountain respectively.

The study is covering almost entire Europe where as other studies are highly localized and the period considered for this study is of 6 decades (1950-2010). For example Heikkila et al. [38] studies the model performance with the WRF model is for Norway region (for the period of 1961-1990) and they reported that the model bias is of $33.4 \%$ whereas in this study it is $15 \%$ for entire region. They also reported that the use of higher resolution reduces the bias of $26.5 \%$ than coarser resolution. Similarly for Portugal region, Soares et al. [39] reported that the WRF model have good skill on simulated precipitation. They also presented the statistical indices between WRF and observations at different time scales. Even though the present study is not focused on any sensitivity aspect, but the results are reasonable agreeing with the study of Daniel et al. [40]. Another advantage of this study is that the boundary conditions updated at 6 hours is taken from NCEP reanalysis data where as other studies of Heikkila et al. [38]; Soares et al. [39]; Daniel et al. [40] used from ECMWF or ERA-Interim data sets. This study addresses the advantages/disadvantages in using NCEP data.

\section{Summary and Conclusions}

The seasonal scale simulations using WRF-ARW mesoscale model over Europe for the 60-year period of 19512010 in a hindcast mode demonstrate the potential of the model for reproducing the rainfall climatology on a re-

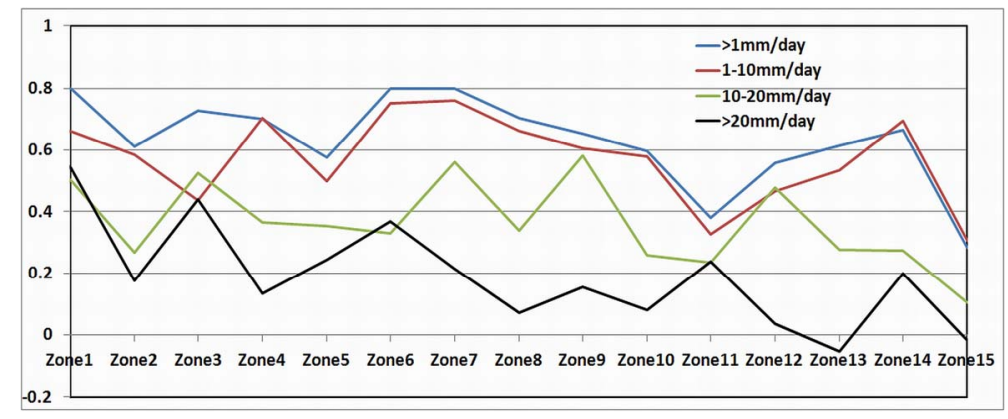

Figure 10. Correlation between model and observed number of rainfall days with different ranges for each zone.

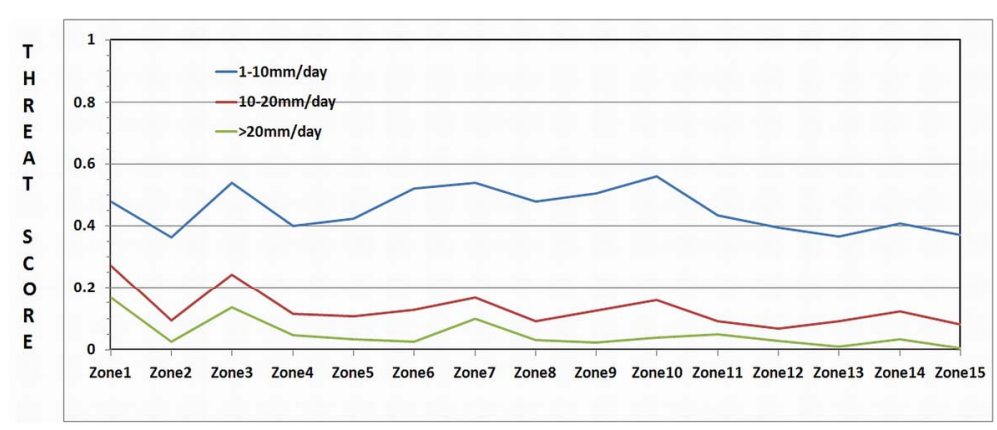

Figure 11. Threat score for different ranges of rainfall days in 60-year period. 
gional scale. The model is run at a moderately high resolution of $25 \mathrm{~km}$ and is forced with 2.5 degree NCEP reanalysis meteorological fields for initial and boundary conditions. Comparisons with observed daily accumulated rainfall climatology (at 0.25 degree resolution) taken from E-OBS over Europe for the above period indicates the model could reproduce the spatial annual rainfall pattern over Europe with low amounts $(250-750 \mathrm{~mm})$ in Iberian peninsula, moderate to large amounts $(750-1500 \mathrm{~mm})$ in central, eastern and northeastern parts of Europe and extremely heavy falls $(1500-2000 \mathrm{~mm})$ in Alps with a slight overestimation in Alps and underestimation in other parts of Europe. Error statistics of model rainfall over different timescales indicated that errors increased with increasing time scale (from daily to seasonal) and relatively better statistics is found for Iberian Peninsula, northwest and western parts of Europe. Relatively high correlations, and less errors (NBIAS, NMAE, NSTDEV) are found at short time scales ( $<5$ days) over Portugal/west Iberian region and central Europe. On the other hand, low correlations and high errors are found over Alps region and Eastern Europe. The simulations could reproduce the decreasing order of frequency of low, heavy, and extremely heavy rainfall events occurrence (for the wet days) as in observed rainfall climate. The simulations have shown large spatial variability with highest number of wet days over eastern, central Europe and Alps ( $\sim 200$ days/year) and less number of wet days over Iberian Peninsula region ( $\leq 150$ days/year) in agreement with observations. An important result from the study is that the model successfully simulated the cumulative rainfall over $1-5$ days time scale, moderately well for 5 - 10 days time scale and with poor correlations for 15 days and higher number of days. The maximum mean number of consecutive dry days and consecutive wet days could also be successfully simulated in good agreement with observations. The simulated rainfall in different zones indicated the model could simulate the spatial rainfall climate variability with low rainfall days $(1-10 \mathrm{~mm} /$ day $)$ well simulated in almost all zones, heavy rainfall events in zones 1, 6, 7, 10,13,15 and extremely heavy rainfall events in zones 6,7 alone. In most zones the number of extreme events is underestimated though time variation trends were found similar as with observations indicating model deficiency for extreme rainfall category. The model could reproduce the decreasing trend of low and moderate rainfall ( $1-10 \mathrm{~mm} /$ day $)$ events in the zones $3,5,7,10-15$ and the increasing trend of heavy rainfall in zones $7,10,12,15$ and decreasing trend in zones 3, 5 and a steady trend of the same in other zones. The model performance for extremely heavy rainfall events is found to be poor in zones $3,4,8,9$, $10,12,13,14$. Threat score analysis showed that the model could predict around $40 \%$ to $60 \%$ of number of observed heavy rainfall events, $10 \%$ to $25 \%$ of observed very heavy rainfall events and only $\leq 20 \%$ of extremely heavy rainfall events. In general, the model could simulate the rainfall climatology over the 60 -year period well especially for the low and heavy rainfall followed by very heavy and extremely heavy rainfall in Europe and the simulation is better for Zones 1, 3, 7 and 10 located in the Iberian west coast, central northern Europe and Alps mountain respectively.

\section{Acknowledgements}

The authors are thankful to Geophysics Centre, University of Evora, Portugal, under the contract with FCT (the Portuguese Science and Technology Foundation), PEst-OE/CTE/UI0078/2011. The authors gratefully acknowledge the NCAR, USA for the public access of WRF-ARW mesoscale model, NCEP/NCAR USA for the reanalysis data sets used in the study. We also acknowledge the E-OBS dataset from the EU-FP6 project ENSEMBLES for making available to use for this study. The authors are grateful to Galicia Supercomputing Center, Spain (http://www.cesga.es/) for permitting to access the super computational facility CESGA to carry out the computations in this work. The 2nd author is thankful to Dr. B. Venkatraman, Associate Director, RSEG, IGCAR for supporting the collaborative study with Geophysics Center, University of Evora, Portugal.

\section{References}

[1] Keeling, C.D., Whorf, T.P., Wahlen, M. and van der Plicht, J. (1995) Interannual Extremes in the Rate of Rise of Atmospheric Carbon Dioxide Since 1980. Nature, 375, 666-670. http://dx.doi.org/10.1038/375666a0

[2] Intergovernmental Panel on Climate Change (IPCC) (1999) Climate Change. A Report of the Intergovernmental Panel on Climate Change, IPCC Report. Geneva, 64 p.

[3] Harries, J.E., Brindley, H.E., Sagoo, P.J. and Bantges, R.J. (2001) Increases in Greenhouse Forcing Inferred from the Outgoing Longwave Radiation Spectra of the Earth in 1970 and 1997. Nature, 410, 355-357. http://dx.doi.org/10.1038/35066553 
[4] Intergovernmental Panel on Climate Change (IPCC) (2001) Climate Change. Volumes 1-3, Third Assessment Report, Intergovernmental Panel on Climate Change. Cambridge University Press, Cambridge.

[5] Giorgi, F. and Mearns, L. (1999) Introduction to Special Section: Regional Climate Modeling Revisited. Journal of Geophysical Research, 104, 6335-6352. http://dx.doi.org/10.1029/98JD02072

[6] Wang, Y., Sen, O.L. and Wang, B. (2003) A Highly Resolved Regional Climate Model (IPRCRegCM) and Its Simulation of the 1998 Severe Precipitation Event over China. Part I: Model Description and Verification of Simulation. Journal of Climate, 16, 1721-1738. http://dx.doi.org/10.1175/1520-0442(2003)016<1721:AHRRCM>2.0.CO;2

[7] Christensen, J.H. and Christensen, O.B. (2003) Severe Summer Time Flooding in Europe. Nature, 421, 805-806. http://dx.doi.org/10.1038/421805a

[8] Mass, C.F., Ovens, D., Westrick, K. and Colle, B.A. (2002) Does Increasing Horizontal Resolution Produce More Skillful Forecasts? Bulletin of the American Meteorological Society, 83, 407-430.

[9] Salathé, E.P., Steed, R., Mass, C.F. and Zahn, P.H. (2008) A High-Resolution Climate Model for the United States Pacific Northwest: Mesoscale Feedbacks and Local Responses to Climate Change. Journal of Climate, 21, 5708-5726. http://dx.doi.org/10.1175/2008JCLI2090.1

[10] Castro, M., Gallardo, C., Jylha, K. and Tuomenvirta, H. (2007) The Use of a Climate-Type Classification for Assessing Climate Change Effects in Europe from an Ensemble of Nine Regional Climate Models. Climatic Change, 81, $329-341$. http://dx.doi.org/10.1007/s10584-006-9224-1

[11] Rummukainen, M. (2010) State-of-the-Art with Regional Climate Models. Vol. 1, John Wiley \& Sons Ltd., Hoboken, 82-96.

[12] Kato, H., Nishizawa, K., Hirakuchi, H., Kadokura, S., Oshima, N. and Giorgi, F. (2001) Performance of RegCM2.5/ NCAR-CSM Nested System for the Simulation of Climate Change in East Asia Caused by Global Warming. Journal of the Meteorological Society of Japan, 79, 99-121. http://dx.doi.org/10.2151/jmsj.79.99

[13] Nicolini, M., Salio, P., Katzfey, J.J., McGregor, J.L. and Saulo, A.C. (2002) January and July Regional Climate Simulation over South America. Journal of Geophysical Research, 107, 4637. http://dx.doi.org/10.1029/2001JD000736

[14] Mearns, L.O., Arritt, R., Biner, S., Bukovsky, M.S., McGinnis, S., Sain, S., Caya, D., Correia Jr., J., Flory, D., Gutowski, W., Takle, E.S., Jones, R., Leung, R., Moufouma-Okia, W., McDaniel, L., Nunes, A.M.B., Qian, Y., Roads, J., Sloan, L. and Snyder, M. (2012) The North American Regional Climate Change Assessment Program: Overview of Phase I Results. Bulletin of the American Meteorological Society, 93, 1337-1362. http://dx.doi.org/10.1175/BAMS-D-11-00223.1

[15] Giorgi, F. and Anyah, R.O. (2012) The Road towards RegCM4. Climate Research, 52, 3-6. http://dx.doi.org/10.3354/cr01089

[16] Giorgi, F., Coppola, E., Solmon, F., Mariotti, L., Sylla, M.B., Bi, X., et al. (2012) RegCM4: Model Description and Preliminary Tests over Multiple CORDEX Domains. Climate Research, 52, 7-29.

[17] Pielke Sr., R.A. (2001) Influence of the Spatial Distribution of Vegetation and Soils on the Prediction of Cumulus Convective Rainfall. Reviews of Geophysics, 39, 151-177. http://dx.doi.org/10.1029/1999RG000072

[18] Pielke Sr., R.A. (2001) Earth System Modeling —An Integrated Assessment Tool for Environmental Studies. In: Matsuno, T. and Kida, H., Eds., Present and Future of Modeling Global Environmental Change: Toward Integrated Modeling, Terra Scientific, Tokyo, 311-337.

[19] Intergovernmental Panel on Climate Change (IPCC) (2007) Climate Change 2007: The Physical Science Basis. Working Group I Contribution to the Fourth Assessment Report of the IPCC. Intergovernmental Panel on Climate Change, Cambridge University Press, New York.

[20] Christensen, J.H., Carter, T.R., Rummukainen, M. and Amanatidis, G. (2007) Evaluating the Performance and Utility of Regional Climate Models: The PRUDENCE Project. Climatic Change, 81, 1-6. http://dx.doi.org/10.1007/s10584-006-9211-6

[21] Takle, E.S., et al. (1999) Project to Inter Compare Regional Climate Simulations (PIRCS): Description and Initial Results. Journal of Geophysical Research, 104, 19443-19462.

[22] Frei, C., Schöll, R., Schmidli, J., Fukutome, S. and Vidale, P.L. (2005) Future Change of Precipitation Extremes in Europe: An Intercomparison of Scenarios from Regional Climate Models. Journal of Geophysical Research, 111, 4124-4137.

[23] Fu, C., Wang, S.Y., Xiong, Z., Gutowski, W.J., Lee, D.K., et al. (2005) Regional Climate Model Intercomparison Project for Asia. Bulletin of the American Meteorological Society, 86, 257-266. http://dx.doi.org/10.1175/BAMS-86-2-257

[24] Van der Linden, P. and Mitchell, J.F.B. (2009) ENSEMBLES: Climate Change and Its Impacts: Summry of Research and Results from ENSEMBLES Project. Met Office Hadley Center, FitzRoy Road, Exter EX1 3PB. 
[25] Christensen, J.H., Kjellström, E., Giorgi, F., Lenderink, G. and Rummukainen, M. (2010) Weight Assignment in Regional Climate Models. Climate Research, 44, 179-194. http://dx.doi.org/10.3354/cr00916

[26] Kjellström, E., Boberg, F., Castro, M., Christensen, J.H., Nikulin, G. and Sánchez, E. (2010) Daily and Monthly Temperature and Precipitation Statistics as Performance Indicators for Regional Climate Models. Climate Research, 44, 135-150. http://dx.doi.org/10.3354/cr00932

[27] Rauscher, S.A., Coppola, E., Piani, C. and Giorgi, F. (2010) Resolution Effect of Regional Climate Model Simulation of Precipitation over Europe. Part I: Seasonal. Climate Dynamics, 35, 685-711. http://dx.doi.org/10.1007/s00382-009-0607-7

[28] Lorenz, P. and Jacob, D. (2010) Validation of Temperature Trends in the ENSEMBLES Regional Climate Model Runs Driven by ERA40. Climate Research, 44, 167-177. http://dx.doi.org/10.3354/cr00973

[29] Boberg, F., Berg, P., Thejll, P., Gutowski, W.J. and Christensen, J.H. (2010) Improved Confidence in Climate Change Projections of Precipitation Further Evaluated Using Daily Statistics from ENSEMBLES Models. Climate Dynamics, 35, 1509-1520. http://dx.doi.org/10.1007/s00382-009-0683-8

[30] Sanchez-Gomez, E., Somot, S. and Déqué, M. (2009) Ability of an Ensemble of Regional Climate Models to Reproduce Weather Regimes over Europe-Atlantic during the Period 1961-2000. Climate Dynamics, 33, 723-736. http://dx.doi.org/10.1007/s00382-008-0502-7

[31] Lenderink, G. (2010) Exploring Metrics of Extreme Daily Precipitation in a Large Ensemble of Regional Climate Model Simulations. Climate Research, 44, 151-166. http://dx.doi.org/10.3354/cr00946

[32] Nikulin, G., Kjellström, E., Hansson, U., Strandberg, G. and Ullerstig, A. (2011) Evaluation and Future Projections of Temperature, Precipitation and Wind Extremes over Europe in an Ensemble of Regional Climate Simulations. Tellus, 63, 41-55. http://dx.doi.org/10.1111/j.1600-0870.2010.00466.x

[33] Herrera, S., Fita, L., Fernández, J. and Gutiérrez, J.M. (2010) Evaluation of the Mean and Extreme Precipitation Regimes from the ENSEMBLES Regional Climate Multimodel Simulations over Spain. Journal of Geophysical Research, 115, D21117. http://dx.doi.org/10.1029/2010JD013936

[34] Herrera, S., Gutiérrez, J., Ancell, R., Pons, M., Frías, M. and Fernández, J. (2012) Development and Analysis of a 50-Year High-Resolution Daily Gridded Precipitation Dataset over Spain (Spain02). International Journal of Climatology, 32, 74-85. http://dx.doi.org/10.1002/joc.2256

[35] Soares, P.M.M., Cardoso, R.M., Miranda, P.M.A., Viterbo, P. and Belo-Pereira, M. (2012) Assessment of the ENSEMBLES Regional Climate Models in the Representation of Precipitation Variability and Extremes over Portugal. Journal of Geophysical Research, 117. http://dx.doi.org/10.1029/2011JD016768

[36] Belo-Pereira, M., Dutra, E. and Viterbo, P. (2011) Evaluation of Global Precipitation Data Sets over the Iberian Peninsula. Journal of Geophysical Research, 116, D20101. http://dx.doi.org/10.1029/2010JD015481

[37] Skamarock, W.C., Klemp, J.B., Dudhia, J., Gill, D.O., Barker, D.M., Duda, M.G., Huang, X.Y., Wang, W. and Powers, J.G. (2008) A Description of the Advanced Research WRF Version 3. NCAR Technical Note, NCAR/TN-475+STR. Mesoscale and Microscale Meteorology Division, National Center for Atmospheric Research, Boulder.

[38] Heikkilä, U., Sandvik, A. and Sorterberg, A. (2010) Dynamical Downscaling of ERA-40 in Complex Terrain Using WRF Regional Climate Model. Climate Dynamics, 36, 845-866.

[39] Soares, P.M.M., Cardoso, R.M., Miranda, P.M.A., Medeiros, J., Belo-Pereira, M. and Espirito-Santo, F. (2012) WRF High Resolution Dynamical Downscaling of ERA-Interim for Portugal. Climate Dynamics, 39, 2497-2522. http://dx.doi.org/10.1007/s00382-012-1315-2

[40] Argüeso, D., Hidalgo-Muñoz, J.M., Gámiz-Fortis, S.R., Esteban-Parra, M.J., Dudhia, J. and Castro-Díez, Y. (2011) Evaluation of WRF Parameterizations for Climate Studies over Southern Spain Using a Multistep Regionalization. Journal of Climate, 24, 5633-5651. http://dx.doi.org/10.1175/JCLI-D-11-00073.1

[41] Argüeso, D., Hidalgo-Muñoz, J.M., Gámiz-Fortis, S.R., Esteban-Parra, M.J. and Castro-Díez, Y. (2012) Evaluation of WRF Mean and Extreme Precipitation over Spain: Present Climate (1970-99). Journal of Climate, 25, 4883-4897. http://dx.doi.org/10.1175/JCLI-D-11-00276.1

[42] Argüeso, D., Hidalgo-Muñoz, J.M., Gámiz-Fortis, S.R., Esteban-Parra, M.J. and Castro-Díez, Y. (2012) High-Resolution Projections of Mean and Extreme Precipitation over Spain Using the WRF Model (2070-2099 vs. 1970-1999). Journal of Geophysical Research, 117, D12108.

[43] Dasari, H.P., Salgado, R., Perdigao, J. and Challa, V.S. (2014) A Regional Climate Simulation Study Using WRFARW Model over Europe and Evaluation for Extreme Temperature Weather Events. International Journal of Atmospheric Sciences, 2014, Article ID: 704079, 22 p.

[44] Hari Prasad, D., Araujo, M.B., Pozo, I. and Ferry, P. (2014) A Regional Climate Change of Summer Temperatures over Iberian Peninsula. Journal of Atmospheric and Climate Sciences.

[45] Hari Prasad, D., Wibig, J. and Repaz, M. (2010) Numerical Modeling of the Severe Cold Weather Event over Central 
Europe (January 2006). Advances in Meteorology, 2010, Article ID: 619478.

[46] Haylock, M., Hofstra, N., Klein-Tank, A., Klok, E.J., Jones, P. and New, M. (2008) A European Daily High-Resolution Gridded Data Set of Surface Temperature and Precipitation for 1950-2006. Journal of Geophysical Research, 113, D20119. http://dx.doi.org/10.1029/2008JD010201

[47] Kalnay, E., Kanamitsu, M., Kistler, R., Collins, W., Deaven, D., Gandin, L., et al. (1996) The NCEP/NCAR 40-Year Reanalysis Project. Bulletin of the American Meteorological Society, 77, 437-471. http://dx.doi.org/10.1175/1520-0477(1996)077<0437:TNYRP $>2.0$. CO;2

[48] Murphy, A.H. and Winkler, R.L. (1987) A General Framework for Forecast Verification. Monthly Weather Review, 115, 1330-1338. http://dx.doi.org/10.1175/1520-0493(1987)115<1330:AGFFFV>2.0.CO;2

[49] Willmott, C.J. (1982) Some Comments on the Evaluation of Model Performance. Bulletin of the American Meteorological Society, 63, 1309-1313. http://dx.doi.org/10.1175/1520-0477(1982)063<1309:SCOTEO >2.0.CO;2

[50] Willmott, C.J., Ackleson, S.G., Davis, R.E., Feddema, J.J., Klink, K.M., Legates, D.R., O’Donnell, J. and Rowe, C.M. (1985) Statistics for the Evaluation and Comparison of Models. Journal of Geophysical Research, 90, 8995-9005. http://dx.doi.org/10.1029/JC090iC05p08995

[51] Jolliffe, I.T. and Stephenson, D.B. (2003) Forecast Verification. A Practitioner's Guide in Atmospheric Science. John Wiley \& Sons Ltd., Hoboken, 240 p.

[52] Wilks, D. (2006) Statistical Methods in the Atmospheric Sciences. Elsevier, San Diego. 